Pol. J. Food Nutr. Sci., 2020, Vol. 70, No. 3, pp. 223-231

DOI: $10.31883 /$ pjfns/120183 http://journal.pan.olsztyn.pl

Original research article

Food Technology Section

\title{
Physical, Physicochemical, Mechanical, and Sensory Properties of Bioplastics from Phosphate Acetylated Arenga Starches
}

\author{
Abdul Rahim ${ }^{1 *}$, Safitri Dombus ${ }^{2}$, Syahraeni Kadir ${ }^{1}$, Muhardi Hasanuddin ${ }^{1}$, \\ Syamsuddin Laude ${ }^{1}$, Jusman Aditya ${ }^{3}$, Steivie Karouw ${ }^{4}$
}

\author{
${ }^{\text {I} F a c u l t y ~ o f ~ A g r i c u l t u r e, ~ T a d u l a k o ~ U n i v e r s i t y, ~ J a l a n ~ S o e k a r n o ~ H a t t a ~ K m .9 ~ N o .32 ~ P a l u, ~ C e n t r a l ~ S u l a w e s i, ~} 94118$ Indonesia \\ ${ }^{2}$ Graduates Faculty of Agriculture, Tadulako University, Jalan Soekarno Hatta Km. 9 No.32 Palu, \\ Central Sulawesi, 94118 Indonesia \\ ${ }^{3}$ Faculty of Mathematics and Natural Science, Tadulako University, Jalan Soekarno Hatta Km. 9 No.32 Palu, \\ Central Sulawesi, 94118 Indonesia \\ ${ }_{4}^{4}$ Indonesian Palm Crops Research Institute, Jalan Raya Mapanget PO BOX 1004 Manado Nort Sulawesi, Indonesia
}

Key words: native arenga starch, acetylation, cross-linking, sodium trimetaphosphate, sodium tripolyphosphate, biofilms

\begin{abstract}
Bioplastics are alternative to plastic packaging made from renewable natural materials. They have a great potential for wider application due to their environmental-friendliness and ease of degradation. This research, therefore, aimed to evaluate the physical, physicochemical, mechanical, and sensory characteristics of bioplastics made from native arenga starch (NAS) and phosphate acetylated arenga starch (PAAS). The PAAS was obtained by dual modification of NAS through acetylation using 5\% acetic anhydride and crosslinking using a mixture of sodium trimetaphosphate (STMP) and sodium tripolyphosphate (STPP) at 99:1 (w/w). The concentrations of the mixture were varied at 2, 4, 6, 8, 10, and 12\% $(w / w)$ of the starch. The thickness, water holding capacity (WHC), oil holding capacity (OHC), water vapor transmission rate (WVTR), water content, biodegradation, Fourier transform infrared (FT-IR) spectroscopy, tensile strength, elongation at break, Young's modulus, and sensory properties of the NAS and PAAS bioplastics were investigated. The results showed the thickness of the NAS and PAAS was generally uniform. The WHC of the NAS bioplastic was higher than that of PAAS. The OHC and WVTR of the PAAS bioplastics increased with the increment in the concentration of the STMP/STPP mixture. Furthermore, the water content of the PAAS bioplastics was lower than that of NAS, while the weight loss due to biodegradation of the NAS was higher compared to PAAS. The PAAS bioplastics were characterized by FTIR, which confirmed the acetylation and crosslinking between the arenga starch molecules. Generally, the elongation at break of the PAAS bioplastics was higher than that of the NAS bioplastic, color of the PAAS bioplastics was more transparent and texture of the PAAS bioplastics surface was smoother than of the NAS bioplastic.
\end{abstract}

\section{INTRODUCTION}

Packaging is the final part of the processes involved in the production of food and non-food products purposely to increase shelf life, improve consumer acceptance, and as a means of providing support for the distribution and expansion of product marketing [Prasteen et al., 2018]. The major material used for this purpose is plastic and this has led to a continuous increase in its waste thereby causing environmental pollution because it is non-biodegradable, its recycling process is quite expensive, and it has the ability to contaminate foods [Ogunrinola \& Akpan, 2018]. There is, however, the urgent need to find alternative materials for packaging and one of these is the bioplastics due to its safe and biodegradable nature.

Bioplastics are produced from renewable natural materials and have been observed to have the potentials of being

\footnotetext{
* Corresponding Author: Tel.: +62451429738; Mobile number:

+6285397897809; E-mail: a pahira@yahoo.com (A. Rahim)
}

an alternative to plastic packaging due to their environmental friendliness and easy degradation. Therefore, there is an urgent need for bioplastics due to the rapid increase in the pace of plastic production and air pollution causing several health risks because of their toxic nature [Jain \& Tiwari, 2015]. Bioplastics are, however, very suitable alternatives to improve the quality of life and maintain a pollution-free planet [Keziah et al., 2018].

It has been discovered that bioplastics made from native starch have poor physicochemical, mechanical, functional and sensory characteristics compared to those modified chemically. According to Shindu \& Khatkar [2018], those produced from modified wheat starch are transparent, have greater tensile strength, and lower solubility compared to the native wheat starch. Moreover, edible films of acetylated rice starch were also found to be stable to heat, have high elongation at break, and a rapid process of degradation [Collusi et al., 2017]. Meanwhile, the mechanical properties of bioplastics from tapioca starch modified using acetic anhydride were observed to be superior over these of the native starch 
[Tawakaltu et al., 2015]. The elongation at break, solubility, and oxygen permeability characteristics of biodegradable films from hydroxypropyl sago starch were higher and the water vapor transmission rate was lower compared to the native material [Polnaya et al., 2013].

One of the potential starches to be used as a bioplastic polymer was native arenga starch (NAS), but it is limited by fast retrogradation, inability to withstand acidic conditions, low viscosity, and paste resistance [Rahim et al., 2019]. Therefore, there is a need for its modification in order to obtain its suitable properties required by bioplastic polymer materials. The novelty of this research was the use of dual modification of the main raw material through acetylation and crosslinking. This involved the development of a phosphate acetylated arenga starch (PAAS) through acetylation and crosslinking. These were intended to produce a modified material that is difficult to retrograde, stable to heat and acids, and resistant to water due to the presence of acetyl groups and crosslinking in the starch molecules. This was possible because previous studies have reported the incorporation of acetyl and phosphate in starch molecules was able to inhibit the retrogradation process and aid resistance to heat, acid-base, and water [Rahim et al., 2017]. Therefore, the objective of this research was to evaluate the physical, physicochemical, mechanical, and sensory characteristics of the NAS and PAAS bioplastics obtained through acetylation using 5\% acetic anhydride and crosslinked using a mixture of sodium trimetaphosphate (STMP) and sodium tripolyphosphate (STPP) at 99:1 (w/w) with different concentrations.

\section{MATERIALS AND METHODS}

\section{Materials}

The materials used in the research consisted of NAS extracted from the pith of sugar palm trees (Arenga pinnata). Distilled water and 98\% acetic anhydride were purchased from Sigma-Aldrich (Steinheim, Germany). Hydrochloric acid $(\mathrm{HCl})$, sodium hydroxide $(\mathrm{NaOH})$, STMP, STPP, 96\% ethanol, glycerol, and acetic acid were purchased from Merck (Darmstadt, Germany). All the chemicals used for the bioplastic analysis were of analytical grade.

\section{Arenga starch extraction}

The NAS was prepared according to the method described by Sahari et al. [2014] with some alterations. Arenga pinnata tree was cut down and the stem was then split to release the woody fiber together with the starch from the inward delicate center of its stem. Step by step, water was brought inside the fiber and starch blend got from the stem and was completely massaged by hand. The blend was then separated to permit the water to move through the sifter with starch granules in the mixture. The starch was conceded sufficient opportunity to settle at the base of the compartment, and water was tapped. After that, the starch was kept in an outdoors for momentarily and then dried in the oven for $72 \mathrm{~h}$ at temperature $70^{\circ} \mathrm{C}$.

\section{Preparation of dual modification arenga starch}

Acetylation of NAS was conducted according to the method of Rahim et al. [2015] while crosslinking followed the Koo et al. [2010] approach with a slight modification. The suspension consisting of $100 \mathrm{~g}$ arenga starch and $225 \mathrm{~mL}$ distilled water was stirred using a magnetic stirrer for $1 \mathrm{~h}$ at room temperature. This was followed by the dropwise of acetic anhydride in such a quality as to give $5 \%$ of weight of arenga starch $(v / w)$. The $\mathrm{pH}$ of the suspension was maintained at 8.0 to 8.5 by adding $3 \% \mathrm{NaOH}$. After $60 \mathrm{~min}$, the $\mathrm{pH}$ was increased to 10.5 through the addition of $3 \% \mathrm{NaOH}$. Next, a mixture of STMP/STPP at 99:1 (w/w) was added in such an amount to obtain concentration of 2, 4, 6, 8, 10, and $12 \%$ by weight of arenga starch $(w / w)$. The suspension was again stirred for $30 \mathrm{~min}$ at room temperature and next $0.5 \mathrm{~N} \mathrm{HCl}$ was added until the $\mathrm{pH}$ decreased to 4.5 to end the reaction. After reaction, the suspension was left to sediment for $30 \mathrm{~min}$ and the sediment was washed with distilled water three times and $96 \%$ ethanol once. Next, the sediment was dried in an oven at $60^{\circ} \mathrm{C}$ for $15 \mathrm{~h}$, mashed, and filtered with 100 mesh sieve. The modified arenga starches were called 2, 4, 6, 8, 10, and $12 \%$ PAAS, respectively, and were used as bioplastic polymer materials.

\section{Preparation of bioplastics}

Bioplastic was prepared according to the method developed by Chung et al. [2010] with a slight modification. The NAS and PAAS (2, 4, 6, 8, 10, and 12\%) were weighed to be $10 \mathrm{~g}$, and $150 \mathrm{~mL}$ of distilled water was added. The solutions were heated on a hot plate to a temperature of $100^{\circ} \mathrm{C}$ with stirring after which $10 \mathrm{~mL}$ of acetic acid and $3 \mathrm{~mL}$ of glycerol were added. The heating process continued until the gel started forming. The solution was further stirred for $10 \mathrm{~min}$ and was poured into stainless steel strips and dried at room temperature for 4 days. The bioplastics obtained were analyzed for physical, physicochemical, mechanical, and sensory properties.

\section{Thickness determination}

Bioplastic thickness was measured according to the method proposed by Turhan \& Sabhaz [2004] through the use of calipers. The samples were placed between the jaws of the caliper and the thickness was measured at five different places and the average was calculated.

\section{Water and oil holding capacity determination}

The water and oil holding capacity (WHC and OHC, respectively) were determined using a method developed by Larrauri et al. [1996] with some modification. Briefly, $25 \mathrm{~mL}$ of distilled water or olive oil were added to $250 \mathrm{mg}$ of bioplastic samples, stirred, and the mixture was left at room temperature for $1 \mathrm{~h}$. After centrifugation at 3,500 $\times \mathrm{g}$ for $30 \mathrm{~min}$ (GS 150 Centrifuge, Clements, Sydney, Australia), the residue was weighed and the holding capacity of water and oil was calculated as $g$ of water or oil, respectively per $g$ of dry bioplastic sample.

\section{Water vapor transmission rate determination}

Water vapor transmission rate (WVTR) was determined using the method proposed by Xu et al. [2004]. This involved the production of a saturated salt solution in a chamber using a jar with a diameter of $12 \mathrm{~cm}$ and a height of $15 \mathrm{~cm}$ as well as 
the adjustment of the relative humidity $(\mathrm{RH})$ in the chamber to $75 \%$ by adding a solution of $40 \% \mathrm{NaCl}(w / v)$ at room temperature. Furthermore, an acrylic cup with diameter of $5 \mathrm{~cm}$ and height of $1.8 \mathrm{~cm}$ was filled with $10 \mathrm{~g}$ silica gel, covered with bioplastic according to its size, and placed in the $75 \%$ $\mathrm{RH}$ chamber. The water vapor diffusing through the bioplastics and silica gel added to the weight and the whole setup was weighed every hour for $8 \mathrm{~h}$ to determine the weight gain. The data was used to plot a graph of the time vs. weight, and the slope was recorded to calculate WVTR using the following equation:

$\operatorname{WVTR}\left(\mathrm{g} / \mathrm{h} / \mathrm{m}^{2}\right)=\frac{\text { Change of bioplastics sample weight }(\mathrm{g} / \mathrm{h})}{\text { Surface area of the bioplastics sample }\left(\mathrm{m}^{2}\right)}$

\section{Moisture content determination}

Moisture content was measured following the method applied by AOAC [2005]. The portions of bioplastics $(0.5 \mathrm{~g})$ were dried in an oven at $105^{\circ} \mathrm{C}$ for $2 \mathrm{~h}$.

\section{Biodegradability analysis}

The biodegradability of the bioplastic samples was investigated according to the method developed by Ashok et al. [2018] with slight modification. The samples were cut into $1 \times 4 \mathrm{~cm}$, weighed $\left(\mathrm{W}_{1}\right)$, and buried in the soil at a depth of $8 \mathrm{~cm}$ for a curing duration of 9 days after which they were weighed again $\left(\mathrm{W}_{2}\right)$. The weight loss due to the biodegradation process was determined through the use of the following formula:

$$
\text { Weight loss }(\%)=\frac{\mathrm{W}_{1}-\mathrm{W}_{2}}{\mathrm{~W}_{1}} \times 100 \%
$$

\section{FTIR spectra analysis}

FTIR spectra of NAS and PAAS bioplastics were analyzed according to Diop et al. [2011]. The bioplastics were mixed with $\mathrm{KBr}$ at a ratio of 1:100 (sample: $\mathrm{KBr}, w / w$ ). The infrared spectra were obtained using a Fourier Transform Spectrometer (IR Prestige-21, Shimadzu Corporation, Tokyo, Japan) at a wavenumber range from $4000 \mathrm{~cm}^{-1}$ to $500 \mathrm{~cm}^{-1}$ regions.

\section{Tensile strength, elongation at break, and Young's modulus determination}

Tensile strength and elongation at break were measured using a Mechanical Universal Testing Machine (Model LR30K, LLOYD Instruments Ltd., Hampshire, England). This involved cutting the bioplastics into the required standard and the two ends were clamped to the testing machine at a distance of $50 \mathrm{~mm}$ and a speed of $10 \mathrm{~mm} / \mathrm{min}$. The start knob was turned on and the machine pulled the sample until it broke and the tensile strength and elongation at break values were recorded afterward. The tensile strength was calculated based on the maximum force (N) applied for the material to break divided by the area of the bioplastic $\left(\mathrm{mm}^{2}\right)$ :

$$
\text { Tensile strength }(\mathrm{MPa})=\frac{\mathrm{F}_{\mathrm{Max}}(\mathrm{N})}{\text { Bioplastics surface area }\left(\mathrm{m}^{2}\right)}
$$

The elongation at break was calculated using the equation: Elongation at break $(\%)=\frac{\text { Maximum length }- \text { Initial length }}{\text { Initial length }} \times 100 \%$

Young's modulus was calculated based on the values of tensile strength and elongation at break according to the formula:

$$
\text { Young's modulus }(\mathrm{MPa})=\frac{\text { Tensile strength }}{\text { Elogation at break } / 100}
$$

\section{Sensory evaluation}

The sensory analysis was conducted using a 15-member panel consisting of students from the Faculty of Agriculture, Tadulako University, Central Sulawesi Indonesia. The bioplastic samples were cut into small pieces and the color, texture, aroma, and overall acceptability were tested using a 7-point hedonic scale were 7 indicates highly very like, 6 - very like, 5 - like, 4 - neither like nor dislike, 3 - somewhat like, 2 - dislike, and 1 - very dislike. The panelists were instructed to rate the attributes indicating their degree of likeness using the numbers provided in the hedonic scale according to their preference.

\section{Statistical analysis}

All parameters were determined in triplicate except for thickness and sensory analysis, which were carried out four times. The results were analyzed through the application of oneway ANOVA using SPSS version 22 (SPSS Inc., Chicago, IL, USA). The means were compared with Duncan's multiple tests and the statistical significance was defined at $p \leq 0.05$.

\section{RESULTS AND DISCUSSION}

\section{Thickness}

The thickness of bioplastics of NAS and PAAS obtained using different concentrations of the STMP/STPP mixture are shown in Figure 1. There were no significant differences $(p>0.05)$ in the thickness of both NAS and PAAS bioplastics and this was associated with the equal amount of raw material used. The values $(0.36-0.45 \mathrm{~mm})$ were in line with the findings of Marichelvam et al. [2019] that the average thickness of bioplastics made from corn and rice starch was $0.25 \mathrm{~mm}$ and this means they can be used as biodegradable plastic bags. Moreover, Ghasemlou et al. [2013] reported the thickness of the edible film of corn starch was around $0.15 \mathrm{~mm}$ while Fakhouri et al. [2013] obtained 0.053 to $0.063 \mathrm{~mm}$ for those made from potato, rice, wheat, gelatin, and sorghum starch.

\section{Water and oil holding capacity}

The WHC and OHC of NAS and PAAS bioplastics are shown in Figure 2. The WHC and OHC of NAS bioplastic were significantly different $(\mathrm{p} \leq 0.05)$ from those of the PAAS ones. The highest WHC was found for NAS bioplastic. The PAAS bioplastics had lower WHC, which probably was associated with the presence of cross-linking bonds in the PAAS molecules hindering water penetration. However, the concentration of the STMP/STPP mixture used to obtain 


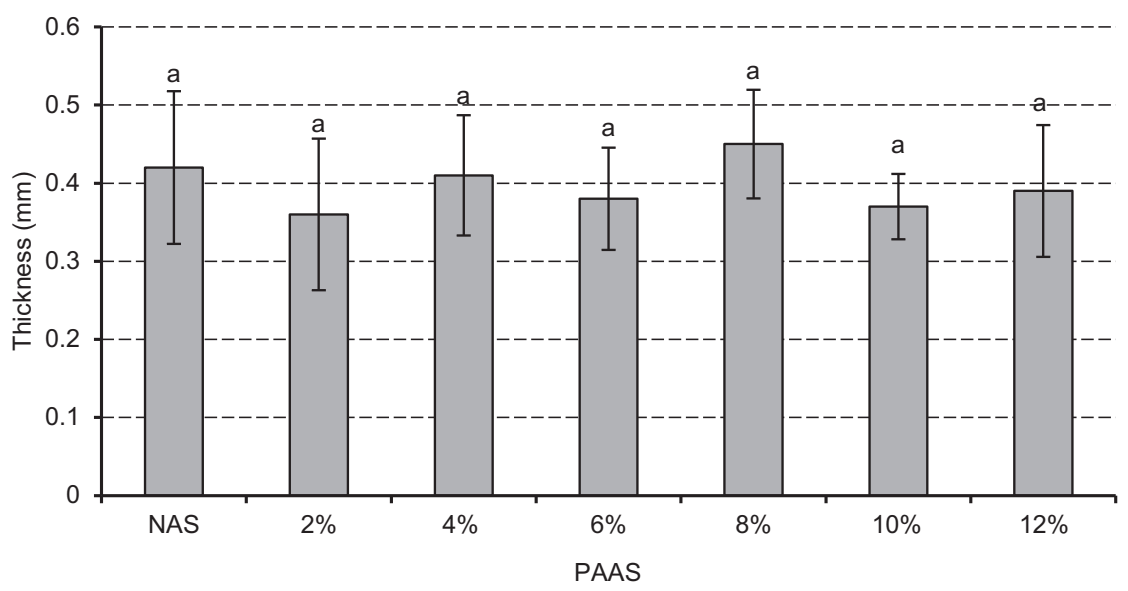

FIGURE 1. Thickness of bioplastics of native arenga starch (NAS) and phosphate acetylated arenga starches (PAAS) obtained using different concentrations of sodium trimetaphosphate/sodium tripolyphosphate (STMP/STPP) mixture (2-12\%).

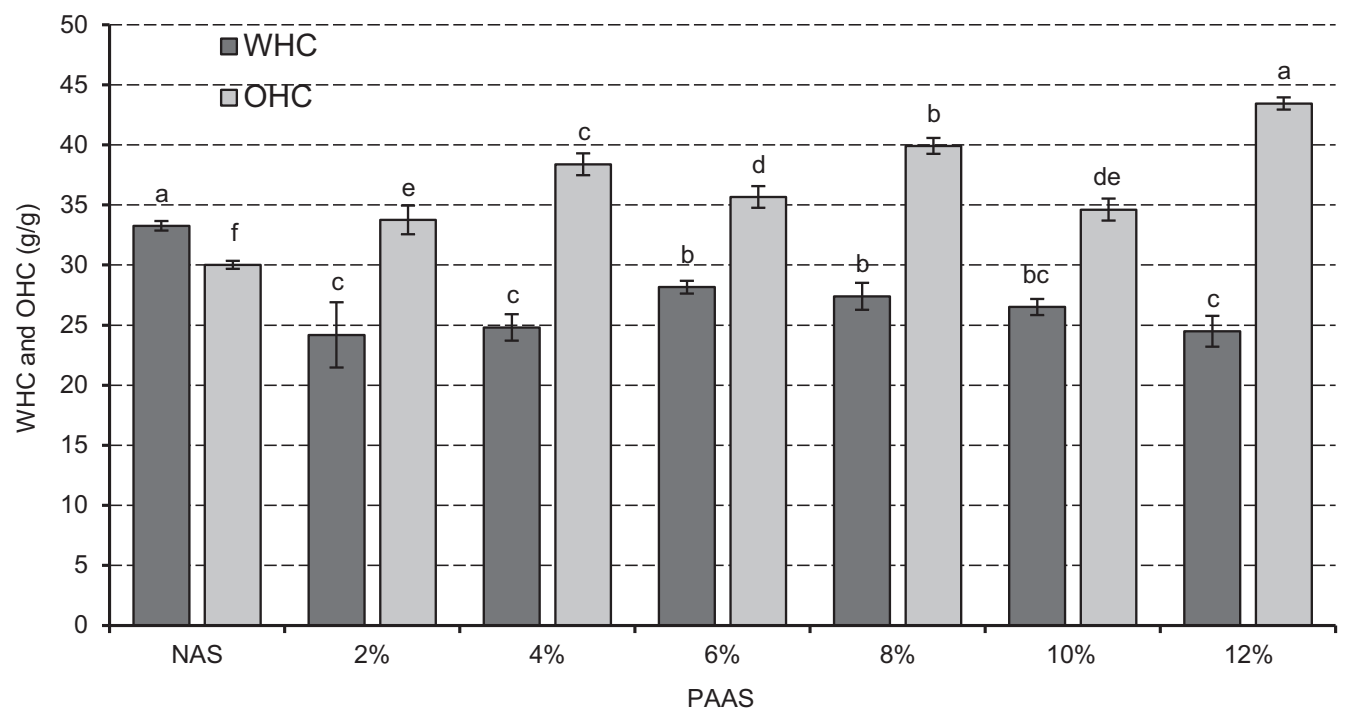

FIGURE 2. The water holding capacity (WHC) and oil holding capacity (OHC) of bioplastics of native arenga starch (NAS) and phosphate acetylated arenga starches (PAAS) obtained using different concentrations of sodium trimetaphosphate/sodium tripolyphosphate (STMP/STPP) mixture $(2-12 \%)$. Different letters a-f above bars indicate significant differences among values $(p \leq 0.05)$.

the modified polymers only slightly differentiated the WHC of PAAS bioplastics. Meanwhile, the highest and lowest OHC were found for $12 \%$ PAAS and NAS bioplastics, respectively. Furthermore, the $\mathrm{OHC}$ tended to be increasing with the increased concentrations of the STMP/STPP mixture.

The WHC results are in agreement with the study that showed the water uptake of bioplastics from cassava peel starch reinforced with microcrystalline cellulose (Avicel PH101fillers) was lower compared to the original material. This was attributed to the strong hydrogen bonds between microcrystalline cellulose and the molecular structure of starch [Maulida et al., 2016]. The OHC results were in accordance with an earlier report of Sondari \& Iltizam [2018] who showed that the OHC of bioplastics from modified cassava starch was lower than that of the original material.

\section{Water vapor transmission rate}

WVTR of the NAS and PAAS bioplastics is presented in Figure 3. The highest WVTR $\left(2.40 \mathrm{~g} / \mathrm{h} / \mathrm{m}^{2}\right)$ was noted for the bioplastic obtained using NAS. The lowest value $(1.05 \mathrm{~g} / \mathrm{h} /$ $\mathrm{m}^{2}$ ) was determined for $4 \%$ PAAS sample, however this value did not differ significantly ( $\mathrm{p}>0.05)$ from those determined for $2 \%$ and $6 \%$ PAAS bioplastics. It is important to note that the values obtained for the PAAS bioplastics were lower than these determined for NAS and this could be associated with the rigidity of PAAS which has the ability to prevent water from entering the starch molecules. Moreover, the incorporation of acetyl groups into the starch molecules has led to a reduction of $\mathrm{OH}$ groups and thus to the lower ability to bind water [López et al., 2011]. This is in accordance with an earlier report of Detduangchan et al. [2014] that the WVTR of the modified rice starch bioplastic was lower than that of the native material.

According to Fakhoury et al. [2012], the water vapor permeability of the native cassava starch film was higher with $4.88 \mathrm{~g} \mathrm{~mm} / \mathrm{m}^{2} \mathrm{~d} \mathrm{kPa}$ compared to acetylated and crosslinked cassava starch, which was found to be $3.59 \mathrm{~g} \mathrm{~mm} / \mathrm{m}^{2} \mathrm{~d} \mathrm{kPa}$. This phenomenon was caused by the strong interaction be- 


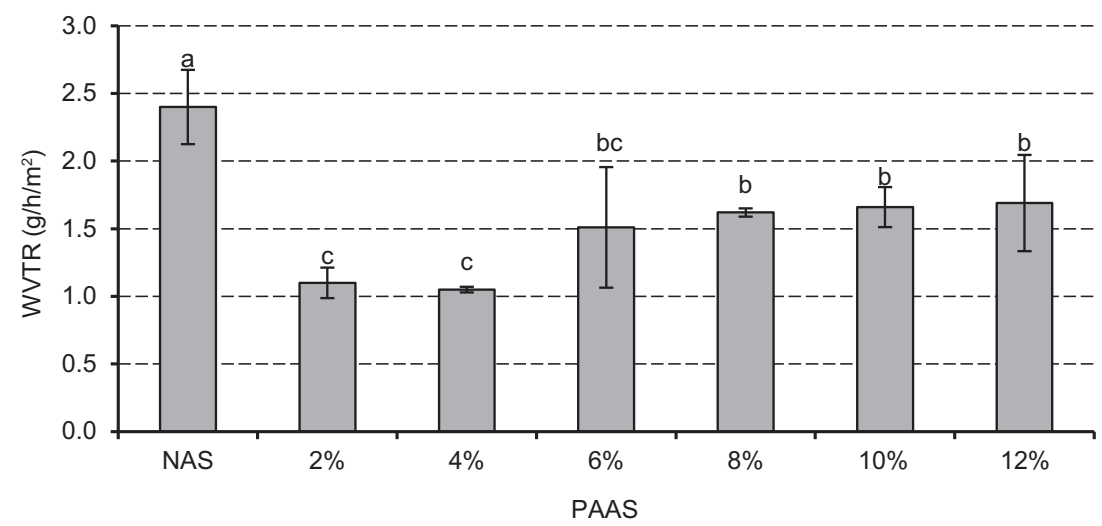

FIGURE 3. The water vapor transmission rate (WVTR) of bioplastics of native arenga starch (NAS) and phosphate acetylated arenga starches (PAAS) obtained using different concentrations of sodium trimetaphosphate/sodium tripolyphosphate (STMP/STPP) mixture (2-12\%). Different letters a-c above bars indicate significant differences among values $(\mathrm{p} \leq 0.05)$.

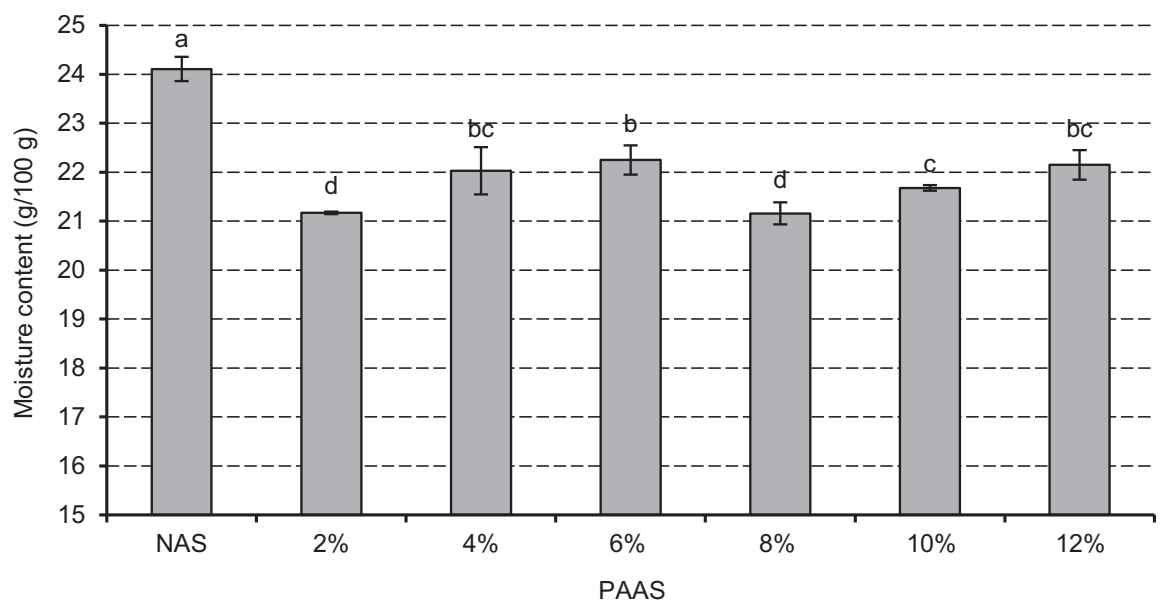

FIGURE 4. Water content of bioplastics of native arenga starch (NAS) and phosphate acetylated arenga starches (PAAS) obtained using different concentrations of sodium trimetaphosphate/sodium tripolyphosphate (STMP/STPP) mixture (2-12\%). Different letters a-d above bars indicate significant differences among values $(\mathrm{p} \leq 0.05)$.

tween amylose and amylopectin in the modified starch molecules. However, bioplastics with a low WVTR value are suitable for packaging food products to avoid damage caused by the surrounding environment.

\section{Water content}

The water content of the NAS and PAAS bioplastics obtained using different concentrations of the STMP/STPP mixture is shown in Figure 4. The concentration of STMP/ STPP mixture significantly $(\mathrm{p} \leq 0.05)$ affected the water contents in PAAS bioplastics. The highest value $(24.11 \mathrm{~g} / 100 \mathrm{~g})$ was obtained for NAS bioplastic, while the lowest (21.16$-21.17 \mathrm{~g} / 100 \mathrm{~g}$ ) was found for $2 \%$ and $8 \%$ PAAS bioplastics. Moreover, the water content in PAAS bioplastics was found to be generally lower than in NAS. It was supported by the findings of Gutiérrez et al. [2015] that the water content in phosphated corn starch edible film was 30\%, compared to $44 \%$ determined in the native corn starch. However, Atef et al. [2015] reported that bioplastics were expected to have a low water content in order to ensure they do not increase the amount of water in the product when used for food packaging.

\section{Biodegradation}

The biodegradability of the bioplastic materials was tested using the soil burial method. Biodegradation is defined as a process of decomposition through the activities of microbes in the soil which leads to the transformation of a compound's structure thereby causing changes in molecular integrity [Liu et al., 2016]. The average values of weight loss for the NAS and PAAS bioplastics are presented in Figure 5. The differences between the values were significant $\mathrm{p} \leq 0.05$ ).

The weight loss was the highest in NAS bioplastic and lower in PAAS samples. However, for PAAS bioplastics, the values increased with the increasing concentrations of the mixture of STMP/STPP used to obtain the modified polymers. This shows NAS bioplastics are more easily degraded compared to PAAS bioplastics. A previous study showed $71 \%$ of potato peel bioplastic degraded in moist soil within four weeks [Arikan \& Bilgen, 2019]. Another research reported the biodegradation of bioplastics made from native corn and rice starches and those modified was influenced by temperature, humidity, and microbial activity such that $48.73 \%$ was achieved after the materials were placed in the soil at a depth of $3 \mathrm{~cm}$ for 15 days [Marchelvam et al., 2019]. 


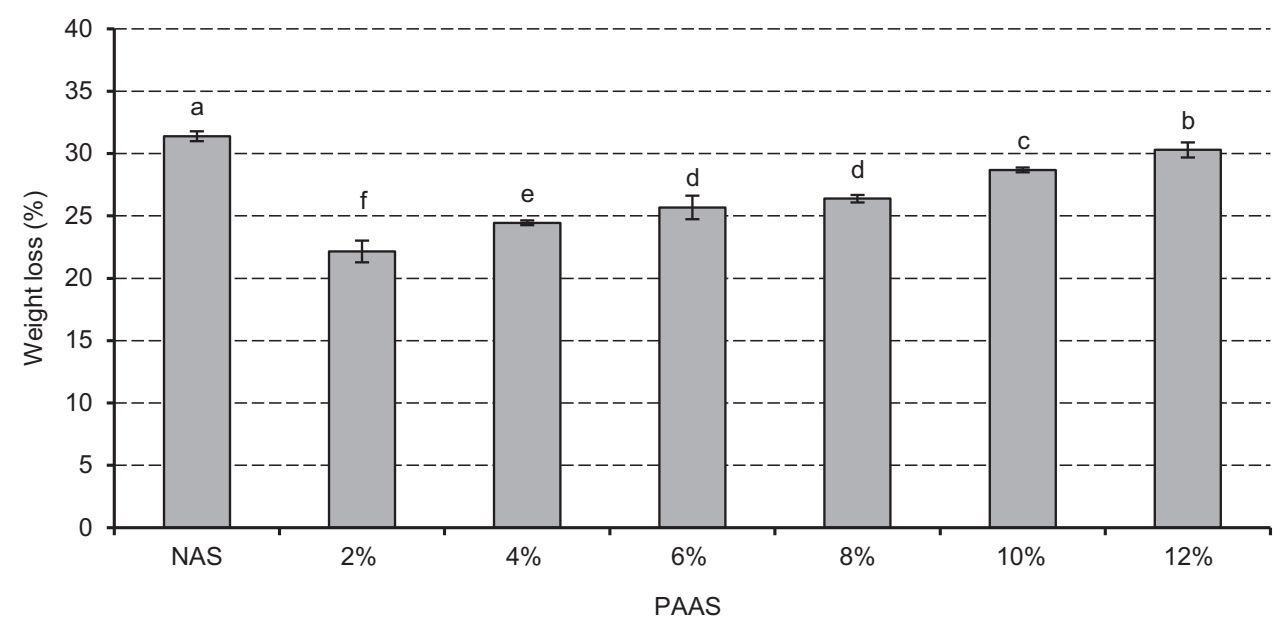

FIGURE 5. Weight loss of bioplastics of native arenga starch (NAS) and phosphate acetylated arenga starches (PAAS) obtained using different concentrations of sodium trimetaphosphate/sodium tripolyphosphate (STMP/STPP) mixture (2-12\%). Different letters a-f above bars indicate significant differences among values $(\mathrm{p} \leq 0.05)$.

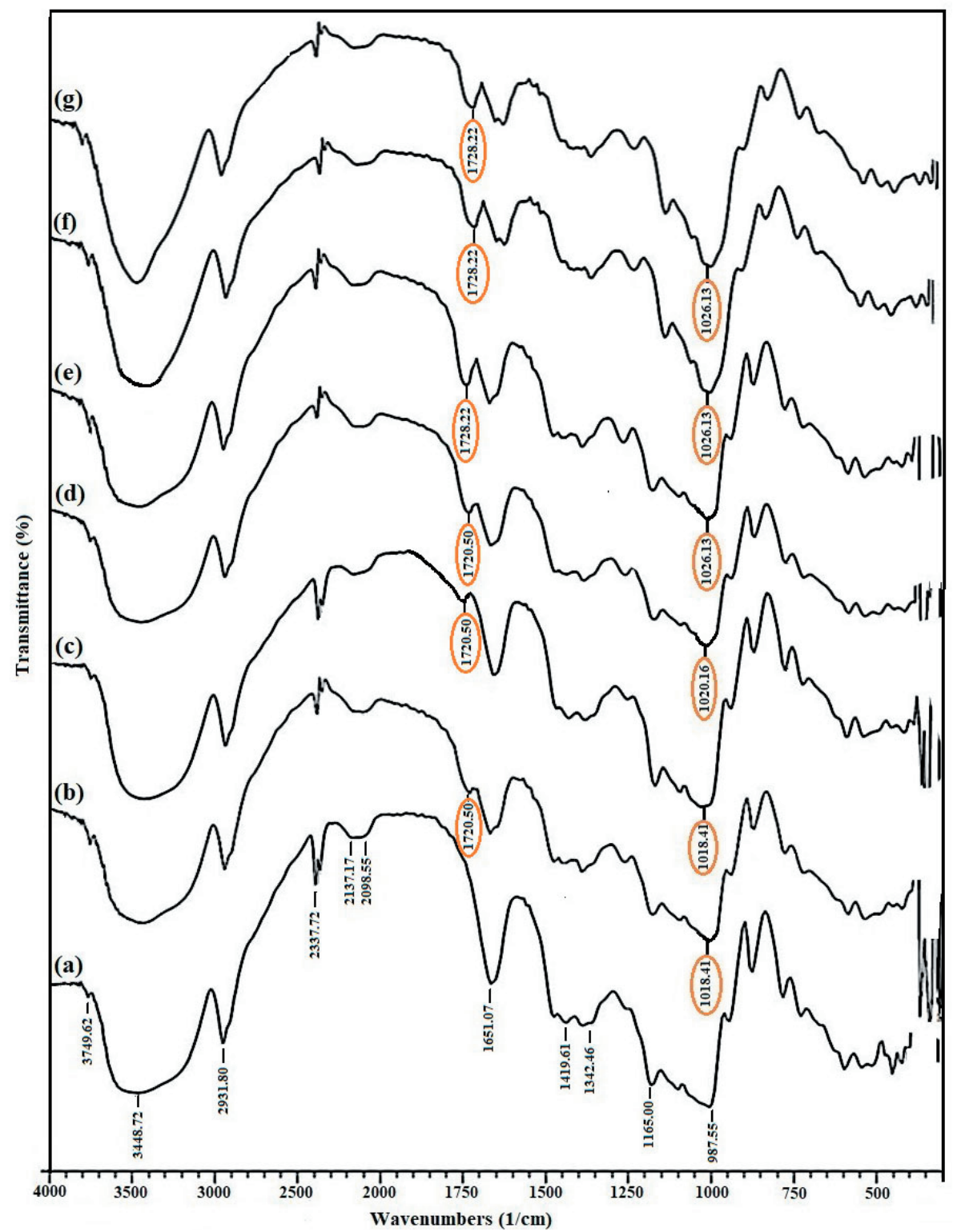

FIGURE 6. The FTIR spectra of bioplastics of native arenga starch (a) and phosphate acetylated arenga starches obtained using different concentrations of sodium trimetaphosphate/sodium tripolyphosphate (STMP/STPP) mixture: $2 \%$ (b), $4 \%$ (c), $6 \%$ (d), $8 \%$ (e), 10\% (f), and 12\% (g). 


\section{FTIR spectra}

FTIR spectra of NAS and PAAS bioplastics are shown in Figure 6. The characteristic bands were observed at the range of $3700 \mathrm{~cm}^{-1}$ to $3000 \mathrm{~cm}^{-1}, 2931.80 \mathrm{~cm}^{-1}$ and $1651.07 \mathrm{~cm}^{-1}$ for the hydroxyl groups $(\mathrm{O}-\mathrm{H})$, methylene $(\mathrm{C}-\mathrm{H})$, and residual bound water $\left(\mathrm{H}_{2} \mathrm{O}\right)$ stretching the vibration of the glucose unit, respectively. In comparison with the values obtained for NAS bioplastic (Figure 6a), the new absorption bands in the range of $1728.22 \mathrm{~cm}^{-1}$ to $1720.50 \mathrm{~cm}^{-1}$ and $1026.13 \mathrm{~cm}^{-1}$ to $1018.41 \mathrm{~cm}^{-1}$ appeared for PAAS bioplastics (Figures $6 \mathrm{~b}-\mathrm{g}$ ). These bands corresponded to $\mathrm{C}=\mathrm{O}$ stretching vibration of an ester group and $\mathrm{P}-\mathrm{O}-\mathrm{C}$ stretching vibration, respectively. This confirmed the occurrence of acetylation and crosslinking between the starch molecules. Previously, acetylation of arenga starch was shown by the presence of the ester carbonyl group bands at $1720 \mathrm{~cm}^{-1}$ [Rahim et al., 2017]. In turn, Detduangchan et al. [2014] reported a peak at $1035.75 \mathrm{~cm}^{-1}$ corresponding to the phosphate stretching (P-O-C) in STMP/STPP cross-linked rice starch films.

\section{Mechanical properties}

The tensile strength, elongation at break, and Young's modulus were determined to evaluate the mechanical properties of NAS and PAAS bioplastics. Tensile strength is the magnitude of the force required to achieve the maximum pull in each bioplastic area. Elongation at break is the percentage change in bioplastic length calculated when it was pulled up to break, whereas the Young's modulus represents the division of the tensile strength by the elongation at break [López et al., 2016]. The average values of these parameters for NAS and PAAS bioplastics are shown in Table 1. The ANOVA indicated that tensile strength of the samples did not differ significantly $(\mathrm{p}>0.05)$, while analysis differentiated bioplastics in terms of elongation at break and Young's modulus $(\mathrm{p} \leq 0.05)$.

Generally, the elongation at break of the PAAS bioplastics was higher than that of NAS bioplastic, although it should be noted that the values determined for NAS and $2 \%, 4 \%$, $12 \%$ PAAS did not differ significantly $(\mathrm{p}>0.05)$. Zhang et al.

TABLE 1. The tensile strength, elongation at break, and Young's modulus of the NAS and PAAS bioplastics obtained using different concentrations of STMP/STPP mixture.

\begin{tabular}{lcccc}
\hline Bioplastic & $\begin{array}{c}\text { Tensile strength } \\
(\mathrm{MPa})\end{array}$ & $\begin{array}{c}\text { Elongation } \\
\text { at break }(\%)\end{array}$ & $\begin{array}{c}\text { Young's modulus } \\
(\mathrm{MPa})\end{array}$ \\
\hline NAS & $1.08 \pm 0.09^{\mathrm{a}}$ & $7.03 \pm 0.83^{\mathrm{b}}$ & $0.15 \pm 0.01^{\mathrm{a}}$ \\
PAAS 2\% & $1.10 \pm 0.12^{\mathrm{a}}$ & $7.87 \pm 1.28^{\mathrm{ab}}$ & $0.14 \pm 0.01^{\mathrm{ab}}$ \\
PAAS 4\% & $1.09 \pm 0.29^{\mathrm{a}}$ & $7.78 \pm 1.45^{\mathrm{ab}}$ & $0.14 \pm 0.04^{\mathrm{ab}}$ \\
PAAS 6\% & $1.16 \pm 0.16^{\mathrm{a}}$ & $9.14 \pm 1.09^{\mathrm{a}}$ & $0.13 \pm 0.02^{\mathrm{ab}}$ \\
PAAS 8\% & $0.94 \pm 0.07^{\mathrm{a}}$ & $8.09 \pm 1.05^{\mathrm{a}}$ & $0.12 \pm 0.01^{\mathrm{b}}$ \\
PAAS 10\% & $0.93 \pm 0.03^{\mathrm{a}}$ & $8.17 \pm 0.54^{\mathrm{a}}$ & $0.11 \pm 0.01^{\mathrm{b}}$ \\
PAAS 12\% & $0.99 \pm 0.11^{\mathrm{a}}$ & $7.87 \pm 1.17^{\mathrm{ab}}$ & $0.13 \pm 0.01^{\mathrm{ab}}$ \\
\hline
\end{tabular}

Data are mean \pm standard deviation (SD). Values in the same column with different superscript indicate a significant difference $(p \leq 0.05)$. NAS = native arenga starch, PAAS = phosphate acetylated arenga starches, $\mathrm{STMP}=$ sodium trimetaphosphate, $\mathrm{STPP}=$ sodium tripolyphosphate.
[2013] reported an increase in elongation at break of oxidized corn starch films due to an increase in the mobility of starch chains resulting from a stronger interaction between oxidized starch and starch chains and a higher degree of oxidation. Moreover, Woggum et al. [2014] also found the elongation at break of dual modified rice starch with a mixture of STMP 2\% - STPP 5\% was higher than that of the native starch.

Furthermore, the elongation at break of the PAAS bioplastics increased with the concentrations of STMP/STPP up to $6 \%$ and subsequently remained constant at $12 \%$. Meanwhile, the Young's modulus of the PAAS bioplastics decreased with the concentrations of STMP/STPP up to $8 \%$ and afterwards remained constant at $12 \%$. However, the elongation at break and Young's modulus of bioplastics from chitosan cross-linking methylcellulose using STMP 0.1 and $0.3 \%$ were found to be higher than these of the chitosan bioplastics [Wang et al., 2019].

\section{Sensory attributes}

The degree of likeness of color, texture, aroma, and overall acceptability of the NAS and PAAS bioplastics were evaluated and the results are presented in Table 2. The color and texture were significantly different $(\mathrm{p} \leq 0.05)$, while the differentiations among bioplastics in aroma and overall acceptability were not significant $(\mathrm{p}>0.05)$.

The color and texture of the PAAS bioplastics were more transparent and their surface was smoother compared to NAS bioplastic, respectively. The transparency and smoother surface of the PAAS bioplastics were achieved through acetylation and crosslinking. In line with the findings of this research, it was reported that the color of the bioplastics from oxidized, crosslinked, and dual oxidation crosslinked lotus rhizome starch was clearer compared to the native material [Sukhija et al., 2019]. This is in agreement with the report by Wang et al. [2019] who showed the colors and texture of films made from chitosan methylcellulose crosslinking were more transparent and smoother due to the compactness of the starch molecules.

TABLE 2. Sensory assessment of the NAS and PAAS bioplastics obtained using different concentrations of STMP/STPP mixture.

\begin{tabular}{lcc|c|c}
\hline Bioplastic & Color & Texture & Aroma & $\begin{array}{c}\text { Overall } \\
\text { acceptability }\end{array}$ \\
\hline NAS & $4.60 \pm 0.74^{\mathrm{b}}$ & $4.60 \pm 1.12^{\mathrm{b}}$ & $4.48 \pm 1.13^{\mathrm{a}}$ & $5.33 \pm 0.72^{\mathrm{a}}$ \\
PAAS 2\% & $5.40 \pm 0.63^{\mathrm{a}}$ & $5.47 \pm 0.99^{\mathrm{a}}$ & $4.60 \pm 0.83^{\mathrm{a}}$ & $5.33 \pm 0.72^{\mathrm{a}}$ \\
PAAS 4\% & $5.27 \pm 0.88^{\mathrm{ab}}$ & $5.53 \pm 0.92^{\mathrm{a}}$ & $4.73 \pm 0.70^{\mathrm{a}}$ & $5.53 \pm 0.83^{\mathrm{a}}$ \\
PAAS 6\% & $4.93 \pm 0.88^{\mathrm{ab}}$ & $5.47 \pm 0.99^{\mathrm{a}}$ & $4.53 \pm 0.64^{\mathrm{a}}$ & $5.60 \pm 0.63^{\mathrm{a}}$ \\
PAAS 8\% & $5.67 \pm 1.11^{\mathrm{a}}$ & $5.27 \pm 0.96^{\mathrm{ab}}$ & $5.07 \pm 0.88^{\mathrm{a}}$ & $5.47 \pm 0.64^{\mathrm{a}}$ \\
PAAS 10\% & $5.13 \pm 0.99^{\mathrm{ab}}$ & $5.20 \pm 0.86^{\mathrm{ab}}$ & $5.07 \pm 0.96^{\mathrm{a}}$ & $5.20 \pm 0.68^{\mathrm{a}}$ \\
PAAS 12\% & $5.07 \pm 1.03^{\mathrm{ab}}$ & $5.13 \pm 0.74^{\mathrm{ab}}$ & $4.73 \pm 1.03^{\mathrm{a}}$ & $5.20 \pm 0.68^{\mathrm{a}}$ \\
\hline
\end{tabular}

Data are mean \pm standard deviation (SD). Values in the same column with different superscript indicate a significant difference $(p \leq 0.05)$. NAS = native arenga starch, PAAS = phosphate acetylated arenga starches, $\mathrm{STMP}=$ sodium trimetaphosphate, $\mathrm{STPP}=$ sodium tripolyphosphate. 


\section{CONCLUSION}

The dual modification of NAS by acetylation and phosphorylation using STMP/STPP mixture with $2-12 \%$ concentrations proved to be an advantageous strategy to obtain the PAAS bioplastics with improved physicochemical, mechanical, and sensory properties compared to NAS bioplastic. The WHC, WVTR, moisture content, and Young's modulus of the PAAS bioplastics were generally lower than these of the NAS bioplastic, while the $\mathrm{OHC}$ and elongation at break of the PAAS bioplastics were higher compared to NAS bioplastics. The NAS and PAAS bioplastics were decomposed in the soil. Furthermore, the color and texture of the PAAS bioplastics were more transparent and smoother than these of the NAS bioplastic, respectively. This has indicated that the PAAS bioplastics were superior over the NAS bioplastic.

\section{ACKNOWLEDGEMENT}

The authors appreciate the laboratory staff of Agricultural Processing Technology, Faculty of Agriculture, Tadulako University, Central Sulawesi Indonesia for their useful contributions.

\section{RESEARCH FUNDING}

The authors are grateful to the Ministry of Research, Technology and Higher Education for financial support through the Basic Research Scheme with Contract Number: 100/SP2H/LT/DRPM/2019 dated March 21, 2019.

\section{CONFLICT OF INTERESTS}

The authors declare there is no conflict of interest.

\section{REFERENCES}

1. AOAC International 2005. Method 926.08. Official Methods of Analysis. 18th ed. AOAC International, Gaithersburg, MD, USA: AOAC International.

2. Arikan, E.B., Bilgen, H.D. (2019). Production of bioplastic from potato peel waste and investigation of its biodegradability. International Advanced Researches and Engineering Journal, 3(2), 93-97.

3. Ashok, A., Abhijith, R., Rejeesh, C.R. (2018). Material characterization of starch derived biodegradable plastics and its mechanical property estimation. Materials Today: Proceedings, 5(1), 2163-2170.

4. Atef, M., Rezaei, M., Behrooz, R. (2015). Characterization of physical, mechanical, and antibacterial properties of agar-cellulose bionanocompasite films incorporated with savory essential oil. Food Hydrocolloids, 45, 150-157.

5. Chung, Yi-Lin, Ansari, S., Estevez, L., Hayrapetyan, S., Giannelis, G.P., Lai, H.M. (2010). Preparation and properties of biodegradable starch-clay nanocomposites. Carbohydrate Polymers, 79(2), 391-396.

6. Colussi, R., Pinto, V.Z., Halal, S.L.M.E., Biduski, B., Prietto, L., Castilhos, D.D., Zavareze, E.R., Dias, A.R.G. (2017). Acetylated rice starches films with different levels of amylose: Mechanical, water vapor barrier, thermal, and biodegradability properties. Food Chemistry, 221, 1614-1620.

7. Detduangchan, N., Sridach, W., Wittaya, T. (2014). Enhancement of the properties of biodegradable rice starch films by using chemical crosslinking agents. International Food Research Journal, 21(3), 1225-1235.

8. Diop, C., Li, H.L., Xie, B.J., Shi, J. (2011). Effects of acetic acid/ acetic anhydride ratios on the properties of corn starch acetates. Food Chemistry, 126(4), 1662-1669.

9. Fakhouri, F.M., Cost, D., Yamashita, F., Martelli, S.M., Jesus, R.C., Alganer, K.,Collares Quiros, F.P., Innocentini-Mei, L.H. (2013). Comparative study of processing methods for starch gelatin films. Carbohydrate Polymers, 95(2), 681-689.

10. Fakhoury, F.M., Maria, M.S., Canhadas-Bertan, L., Yamashita, F., Innocentini-Mei, L.H., Collares, Q.F.P. (2012). Edible films made from blends of manioc starch and gelatin - Influence of different types of plasticizer and different levels of macromolecules on their properties. LWT - Food Science and Technology, 49, 149-154.

11. Ghasemlou, M., Aliheidari, N., Fahmi, R., Shojaee Aliabadi, S., Keshavarz, B., Cran, M.J., Khaksar, R. (2013). Physical, mechanical and barrier properties of corn starch films incorporated with plant essential oils. Carbohydrate Polymers, 98, 1117-1126.

12. Gutiérrez, T.J., Tapia, M.S., Pérez, E., Famá, L. (2015). Edible films based on native and phosphated 80:20 waxy:normal corn starch. Starch/Starcke, 67(1-2), 90-97.

13. Jain, R., Tiwari, A. (2015). Biosynthesis of planet friendly bioplastics using renewable carbon source. Journal of Environmental Health Science and Engineering, 13(1), art. no. 11.

14. Keziah, V.S., Gayathri, R., Priya, V.V. (2018). Biodegradable plastic production from corn starch. Drug Invention Today, 10(7), $1315-1317$.

15. Koo, Hyun, S., Lee, K.Y., Lee, H.G. (2010). Effect of cross-linking on the physicochemical and physiological properties of corn starch. Food Hydrocolloids, 24(6-7), 619-625.

16. Larrauri, J.A., Ruperez, P., Borroto, B., Saura-Calixto, S. (1996). Mango peels as a new tropical fibre: Preparation and characterization. LWT - Food Science and Technology, 29, 729-733.

17. Liu, W.W., Xue, J., Cheng, B.J., Zhu, S.W., Ma, Q., Ma, H. (2016). Anaerobic biodegradation, physical and structural properties of normal and high-amylose maize starch films. International Journal of Agricultural and Biological Engineering, 9(5), 184-193.

18. López de Dicastillo, C., Rodríguez, F., Guarda, A., Galotto, M.J. (2016). Antioxidant films based on cross-linked methyl cellulose and native Chilean berry for food packaging applications. Carbohydrate Polymers, 136, 1052-1060.

19. López, O.V., Lecot, C.J., Zaritzky, N.E., García, M.A. (2011). Biodegradable packages development from starch based heat sealable films. Journal of Food Engineering, 105, 254-263.

20. Marichelvam, M.K., Jawaid, M., Asim, M. (2019). Corn and rice starch-based bio-plastics as alternative packaging materials. Fibers, 7(4), art. no. 32.

21. Maulida, Siagian, M., Tarigan, P. (2016). Production of starch based bioplastic from cassava peel Reinforced with microcrystalline cellulose Avicel PH101 using sorbitol as plasticizer. Journal of Physics: Conference Series, 710(1), art. no. 012012.

22. Ogunrinola, T.M., Akpan, U.G. (2018). Production of cassava starch bioplastic film reinforced with Poly-Lactic Acid (PLA). 
International Journal of Engineering Research and Advanced Technology, 4(8), 56-61.

23. Polnaya, F.J., Haryadi, Marseno, D.W., Cahyanto, M.N. (2013). Effects of phosphorylation and cross-linking on the pasting properties and molecular structure of sago starch. International Food Research Journal, 20(4), 1609-1615.

24. Prasteen, P., Thushyanthy, Y., Mikunthan, T., Prabhaharan, M. (2018). Bio-plastics - An alternative to petroleum based plastics. International Journal of Research Studies in Agricultural Sciences, 4(1), 1-7.

25. Rahim, A., Kadir, S., Jusman, J. (2015). Chemical and functional properties of acetylated arenga starches prepared at different reaction time. International Journal of Current Research in Biosciences and Plant Biology, 2(9), 43-49.

26. Rahim, A., Kadir, S., Jusman, J. (2017). The influence degree of substitution on the physicochemical properties of acetylated arenga starches. International Food Research Journal, 24(1), 102-107.

27. Rahim, A., Kadir, S., Jusman, J., Zulkipli, Z., Hambali, T.N.A. (2019). Physical, chemical and sensory characteristics of bread with different concentrations of acetylated arenga starches. International Food Research Journal, 26(3), 841-848.

28. Sahari, J., Sapuan, S.M., Zainudin, E.S., Maleque, M.A. (2014), Physicochemical and thermal properties of starch derived from sugar palm tree (Arenga pinnata). Asian Journal Chemistry, 26(4), 955-959.

29. Sindhu, R., Khatkar, B.S. (2018). Development of edible films from native and modified starches of common buckwheat. International Advanced Research Journal in Science, Engineering and Technology, 5(3), 9-12.

30. Sondari, D., Iltizam, I. (2018). Effect of hydrogen peroxide on edible film from cassava starch. AIP Conference Proceedings, 2026 (October).
31. Sukhija, S., Singh, S., Riar, C.S. (2019). Development and characterization of biodegradable films from whey protein concentrate, psyllium husk and oxidized, crosslinked, dual-modified lotus rhizome starch composite. Journal of the Science of Food and Agriculture, 99(7), 3398-3409.

32. Tawakaltu, A.R.A., Egwim, E.C., Ochigbo, S.S., Ossai, P.C. (2015). Effect of acetic acid and citric acid modification on biodegradability of cassava starch nanocomposite films. Journal of Materials Science and Engineering, B 5(9-10), 372-379.

33. Turhan, K.N., Sahbaz, F. (2004). Water vapor permeability, tensile properties and solubility of methylcellulose-based edible film. Journal of Food Engineering, 61 (3), 459-466.

34. Wang, H., Liao, Y., Wu, A., Li, B., Qian, J., Ding, F. (2019). Effect of sodium trimetaphosphate on chitosan-methylcellulose composite films: Physicochemical properties and food packaging application. Polymers, 11 (2), art. no. 368.

35. Woggum, T., Sirivongpaisal, P., Wittaya, T. (2014). Properties and characteristics of dual-modified rice starch based biodegradable films. International Journal of Biological Macromolecules, 67, 490-502.

36. Xu, Y., Miladinov, V., Hanna, M.A. (2004). Synthesis and characterization of starch acetates with high substitution. Cereal Chemistry Journal, 81 (6), 735-740.

37. Zhang, Y.R., Wang, X.L., Zhao, G.M., Wang, Y.Z. (2013). Influence of oxidized starch on the properties of thermoplastic starch. Carbohydrate Polymers, 96, 358-364.

Submitted: 3 November 2019. Revised: 25 February, 27 March, and 5 April 2020. Accepted: 7 April 2020. . Published on-line: 25 May 2020 . 
